\title{
Some Degree-based Connectivity Indices of Tadpole Graph
}

\author{
Kavitha B N, K Srinivasa Rao, Nagabhushana C S
}

\begin{abstract}
Zagreb indices (thought this paper we denote ZbI) a well-known concept introduced in 1972 by I.Gutman and N.Trinajstic denoted as $M_{1}(G)$ mathematically to study chemical compounds at molecular level. The first two hyper-ZbI of $G$ denoted $\mathrm{HM}_{1}(G)$ and $\mathrm{HM}_{2}(G)$ are well established. In this paper we determine the first $\mathrm{ZbI}$ and second $\mathrm{ZbI}$ and their polynomial for the Tadpole graph.
\end{abstract}

Index Terms: Hyper-Zagreb indices, Tadpole graph.

\section{INTRODUCTION}

Throughout this research article we are considering finite, connected, undirected simple graph $G$. We denote $V(G)$ represent the set consists of vertices and $E(G)$ represent the set consists of edges of respectively. $d_{G}(v)$ is the number of vertices adjacent to $v$. We refer [16].

In theoretical chemistry distinctive atomic structures are frequently demonstrated utilizing sub-atomic graphs. Representation of atoms as vertices and bonds as edges respectively and named it as molecular graph.

A sub-atomic diagram is a graph in which, it compares the vertices and edges as to molecules and bonds, individually. In Chemical sciences, synthetic chart hypothesis made exceptionally powerful advancement, and furthermore a topological list for a diagram is utilized to decide some property of the chart sub-atomic by a solitary number. The first $\mathrm{ZbI}$ as well as second $\mathrm{ZbI}$ of a graph $G$ represents topological indices on the basis of degree with respect to the vertices of $G$.

By definition the first $\mathrm{ZbI}$ of a graph $G$ is denoted as $M_{1}(G)$ and is given by $M_{1}(G)=\sum_{v \in V(G)} d_{G}(v)^{2}$ or $M_{1}(G)=$ $\sum_{v_{1} v_{2} \in E(G)}\left[d_{G}\left(v_{1}\right)+d_{G}\left(v_{2}\right)\right]$ and second $\mathrm{ZbI}$ of a graph $G$ is denoted as $M_{2}(G)$ and is given by $M_{2}(G)=\sum_{v_{1} v_{2} \in E(G)}\left[d_{G}\left(v_{1}\right) d_{G}\left(v_{2}\right)\right]$. In [15] Gutman and Trinajstic introduced the concept of degree based on topological indices.

In the papers $[4,11,12 \& 19]$ we obtain the history, applications and characteristics of Zagreb indices.

Shirdel et al. [6] defined first hyper ZbI ( HZbI) of $G$ denoted by $H M_{1}(G)$ and is given by $H M_{1}(G)=$ $\sum_{v_{1} v_{2} \in E(G)}\left[d_{G}\left(v_{1}\right)+d_{G}\left(v_{2}\right)\right]^{2}$ and Farahani et. al. [10], introduced the concept of second HZbI of $G$ denoted as $\mathrm{HM}_{2}(G)$ and is given by $H M_{2}(G)=\sum_{v_{1} v_{2} \in E(G)}\left[d_{G}\left(v_{1}\right) d_{G}\left(v_{2}\right)\right]^{2}$. Authors In [12],[16] and [19] studied these concepts for the comparative advantages of HZbI and other degree based topological indices.

The first Zagreb polynomials (Z Polynomial) of graph $G$ is denoted and defined as $M_{1}(G, x)=\sum_{v_{1} v_{2} \in E(G)} x^{d_{G}\left(v_{1}\right)+d_{G}\left(v_{2}\right)}$ and the second $\mathrm{Z}$ polynomials of $G$ gives the equation $M_{2}(G, x)=\sum_{v_{1} v_{2} \in E(G)} x^{d_{G}\left(v_{1}\right) \cdot d_{G}\left(v_{2}\right)}$ we refer [8]. For further information on $\mathrm{ZbI}$ and their polynomial we can go through [1].

The first $\mathrm{HZb}$ polynomial of $G$ is well-defined as $H M_{1}(G, x)=\sum_{v_{1} v_{2} \in E(G)} x^{\left[d_{G}\left(v_{1}\right)+d_{G}\left(v_{2}\right)\right]^{2}}$ and second $\mathrm{HZb}$ polynomial of $G$ is represented as $\mathrm{HM}_{2}(G)$ and is given by $H M_{2}(G)=\sum_{v_{1} v_{2} \in E(G)} x^{\left[d_{G}\left(v_{1}\right) d_{G}\left(v_{2}\right)\right]^{2}}$.

The concept of Randic index in graph theory for any simple graph structure $G$ can be represented as $\aleph(G)$ and is defined as $\aleph(G)=\sum_{v_{1} v_{2} \in E(G)} \frac{1}{\sqrt{d_{G}\left(v_{1}\right) d_{G}\left(v_{2}\right)}}$. This index was proposed by Randic in [7].

Another interesting concept of graph theory named as the sum connectivity index (SCI)for any simple graph $G$ is denoted and defined as $X(G)=\sum_{v_{1} v_{2} \in E(G)} \frac{1}{\sqrt{d_{G}\left(v_{1}\right)+d_{G}\left(v_{2}\right)}}$ This topological index was proposed by Zhou and Trinajstic in [20].

In [3], Estrada et.al. introduced concept of chemical graph theory called atom-bond connectivity index $(\mathrm{ABCI})$, which is defined $A B C(G)=\sum_{v_{1} v_{2} \in E(G)} \sqrt{\frac{d_{G}\left(v_{1}\right)+d_{G}\left(v_{2}\right)-2}{d_{G}\left(v_{1}\right) d_{G}\left(v_{2}\right)}}$.

In this section, we conduct some calculations needed to calculate the indices of Zagreb and their polynomials $G$. We use the partition set by the vertex $V_{a}=\left\{v \in V: d_{G}(v)=\right.$ $a\}$ and edge $E_{b}=\left\{e=v_{1} v_{2} \in E: d_{G}\left(v_{1}\right)+d_{G}\left(v_{2}\right)=\right.$ $b\} \operatorname{and} E_{C}^{*}=\left\{e=v_{1} v_{2} \in E: d_{G}\left(v_{1}\right) d_{G}\left(v_{2}\right)=C\right\}$.

Revised Manuscript Received on December 22, 2018.

Kavitha B N, Assistance professor, Department of Mathematics, Sri Venkateshwara College of Engineering, Bangalore- 562157 K Srinivasa Rao, Associate professor, Department of Mathematics, Sri Venkateshwara College of Engineering, Bangalore562157Nagabhushana C S, Professor, Department of Mathematics, H.K.B.K Engineering College, Bangalore -560045 Email ID: kavithabn103@gmail.com, csnagabhushana@gmail.com srinivas.dbpur@gmail.com 


\section{DEFINITIONS}

Definition 2.1: $T_{m, n}$ denotes the tadpole graph constructed by joining a cycle $C_{m}$ to a path $P_{n}$. Wherem $\geq 3$ and $n \geq 1$. Tadpole graph is also called as dragon graph.

Generally, in $G$, vertex set can be denoted as $V(G)$ and set of all edges represents $E(G)$ respectively. Also, the no. of vertices $|V(G)|=m+n$ and no. of edges $|E(G)|=m+$ $n$.

\section{Case 1:}

Vertex and edge partition of tadpole graphs $T_{m, n}$ where $m \geq 3$ and $n=1$

We split $V(G)$ into three subsets $V_{1}, V_{2} \& V_{3}$ as the following three partitions.

$V_{1}=\left\{v \in V(G) ; d_{1}(v)=d_{G}(v)=1\right\} ;\left|V_{1}\right|=1$

$V_{2}=\left\{v \in V(G) ; d_{2}(v)=d_{G}(v)=2\right\} ;\left|V_{2}\right|=m-1$ and

$V_{3}=\left\{v \in V(G) ; d_{3}(v)=d_{G}(v)=3\right\} ;\left|V_{3}\right|=1$

Similarly, we consider edge set $E(G)$ partition of of $G$ as $E_{2,2}, E_{3,1} \& E_{3,2}$. That is,

$E_{2,2}=\left\{u v \in E(G): d_{G}(u)=d_{G}(v)=2\right\} ;\left|E_{1}\right|=m-2$.

$E_{3,2}=\left\{u v \in E(G): d_{G}(u)=3, d_{G}(v)=2\right\} ;\left|E_{2}\right|=2$.

$E_{3,1}=\left\{u v \in E(G): d_{G}(u)=3, d_{G}(v)=1\right\} ;\left|E_{3}\right|=1$.

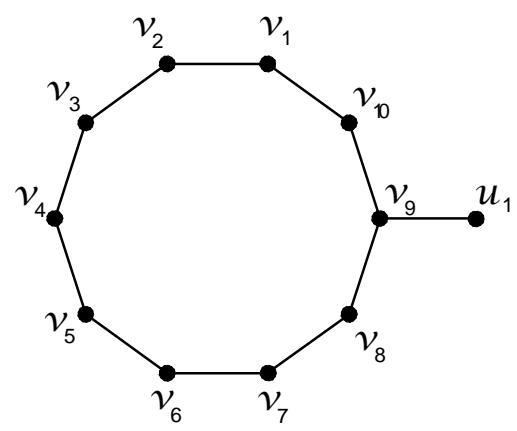

Fig 1: $T_{10,1}$ Graph

Case 2:

Vertex and edge partition of tadpole graphs $T_{m, n}$ where $m \geq$ 3 and $n>1$ is considered below.

In this case we split $V(G)$ into three subsets $V_{1}, V_{2} \& V_{3}$ as the following three partitions.

$V_{1}=\left\{v \in V(G) ; d_{1}(v)=d_{G}(v)=1\right\} ;\left|V_{1}\right|=1$

$V_{2}=\left\{v \in V(G) ; d_{2}(v)=d_{G}(v)=2\right\} ;\left|V_{2}\right|=m+n-2$, and

$$
V_{3}=\left\{v \in V(G) ; d_{3}(v)=d_{G}(v)=3\right\} ;\left|V_{3}\right|=1
$$

Similarly, we consider the partition of edge set $E(G)$ of $G$ as $E_{2,1}, E_{2,2} \& E_{2,3}$. That is,

$E_{2,2}=\left\{u v \in E(G): d_{G}(u)=d_{G}(v)=2\right\} ;\left|E_{1}\right|=m+n-$ 4.

$E_{2,3}=\left\{u v \in E(G): d_{G}(u)=3, d_{G}(v)=2\right\} ;\left|E_{2}\right|=3$.

$E_{2,1}=\left\{u v \in E(G): d_{G}(u)=2, d_{G}(v)=1\right\} ;\left|E_{3}\right|=1$.

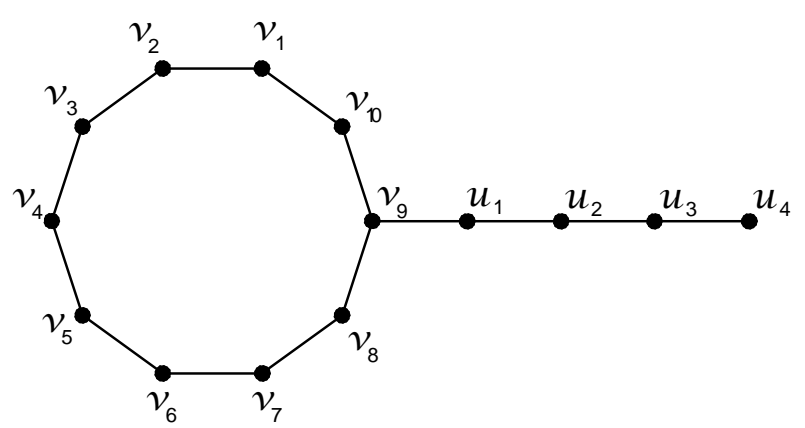

Fig2: $T_{10,4}$ Graph

Theorem 2.1: The first HZbI and their polynomial of a Tadpole graph are

$$
H M_{1}\left(T_{(m, n)}\right)=16 m+34 \text { where } m \geq 3 \text { and } n=1
$$

$H M_{1}\left(T_{m, n}, x\right)=2 x^{25}+(m-1) x^{16}$ where $m \geq 3$ and $n$ $=1$

Proof: Let $G=T_{m, n}$ be a tadpole graph. Let the vertex set $V(G)=\left\{v_{1}, v_{2}, \ldots, v_{n}\right\} \cup\left\{u_{1}, u_{2}, \ldots, u_{n}\right\}$. Where $v_{i} \in V\left(C_{m}\right)$ and $u_{i} \in P_{n}$.

We have,

$$
\begin{aligned}
& H_{1}\left(T_{m, n}\right)=\sum_{v_{1} v_{2} \in E(G)}\left[d_{G}\left(v_{1}\right)+d_{G}\left(v_{2}\right)\right]^{2} \\
& =\sum_{E_{1}}\left[d_{2}\left(v_{1}\right)+d_{2}\left(v_{2}\right)\right]^{2}+\sum_{E_{2}}\left[d_{3}\left(v_{1}\right)+d_{2}\left(v_{2}\right)\right]^{2} \\
& + \\
& \quad \sum_{E_{3}}\left[d_{3}\left(v_{1}\right)+d_{1}\left(v_{2}\right)\right]^{2} \\
& =(m-2)(2+2)^{2}+2(3+2)^{2}+1(3+1)^{2} \\
& =16(m-2)+50+16 \\
& H_{1}\left(T_{m, n}\right)=16 m+34
\end{aligned}
$$

Now for the first hyper-Zagreb polynomial of $T_{m, n}$, we have

$$
\begin{aligned}
& H M_{1}\left(T_{m, n}, x\right)=\sum_{v_{1} v_{2} \in E} x^{\left[d_{G}\left(v_{1}\right)+d_{G}\left(v_{2}\right)\right]^{2}} \\
& =\sum_{E_{1}} x^{\left[d_{2}\left(v_{1}\right)+d_{2}\left(v_{2}\right)\right]^{2}}+\sum_{E_{2}} x^{\left[d_{3}\left(v_{1}\right)+d_{2}\left(v_{2}\right)\right]^{2}} \\
& \quad+\sum_{E_{3}} x^{\left[d_{3}\left(v_{1}\right)+d_{1}\left(v_{2}\right)\right]^{2}} \\
& =(m-2) x^{[2+2]^{2}}+2 x^{[3+2]^{2}}+x^{[3+1]^{2}} \\
& =2 x^{25}+(m-2) x^{16}+x^{16} \\
& H M_{1}\left(T_{m, n}, x\right)=2 x^{25}+(m-1) x^{16}
\end{aligned}
$$

Theorem 2.2: The first HZbI and their polynomial of a Tadpole graph are

$H M_{1}\left(T_{(m, n)}\right)=16 m+16 n+20$ where $m \geq 3$ and $>1$

$H M_{1}\left(T_{m, n}, x\right)=3 x^{25}+(m+n-4) x^{16}$

$$
+x^{9} \quad \text { where } m \geq 3 \text { and } n>1
$$

Proof: Let $G=T_{m, n}$ be a tadpole graph. As defined in theorem 2.1, we consider the vertex set $V(G)$.

Consider

$$
\begin{gathered}
H M_{1}\left(T_{m, n}\right)=\sum_{v_{1} v_{2} \in E(G)}\left[d_{G}\left(v_{1}\right)+d_{G}\left(v_{2}\right)\right]^{2} \\
=\sum_{E_{1}}\left[d_{2}\left(v_{1}\right)+d_{2}\left(v_{2}\right)\right]^{2}+\sum_{E_{2}}\left[d_{3}\left(v_{1}\right)+\right. \\
\begin{aligned}
d 2(v 2) & 2+E 3 d 2 v 1+d 1(v 2) 2 \\
= & (m+n-4)(2+2)^{2}+3(3+2)^{2}+1(2+1)^{2} \\
= & 16(m+n-4)+75+9 \\
= & 16 m+16 n+20
\end{aligned}
\end{gathered}
$$


Now for the first HZb polynomial of $T_{m, n}$, we have

$$
\begin{aligned}
& H M_{1}\left(T_{m, n}, x\right)=\sum_{u v \in E} x^{\left[d_{G}\left(v_{1}\right)+d_{G}\left(v_{2}\right)\right]^{2}} \\
& =\sum_{E_{1}} x^{\left[d_{2}\left(v_{1}\right)+d_{2}\left(v_{2}\right)\right]^{2}}+\sum_{E_{2}} x^{\left[d_{3}\left(v_{1}\right)+d_{2}\left(v_{2}\right)\right]^{2}}+ \\
& \sum_{E_{3}} x^{\left[d_{2}\left(v_{1}\right)+d_{1}\left(v_{2}\right)\right]^{2}} \\
& =(m+n-4) x^{(2+2)^{2}}+3 x^{(3+2)^{2}}+x^{(2+1)^{2}} \\
& =(m+n-4) x^{16}+3 x^{25}+x^{9} \\
& H M_{1}\left(T_{m, n}, x\right)=3 x^{25}+(m+n-4) x^{16}+x^{9}
\end{aligned}
$$

Theorem 2.3: The second HZbI and their polynomial of a Tadpole graph are

$$
\begin{gathered}
H M_{2}\left(T_{(m, n)}\right)=16 m+49 \text { where } m>3 \text { and } n=1 \\
H M_{2}\left(T_{m, n}, x\right)=3 x^{36}+(m-2) x^{16}+x^{4} \text { where } m \\
>3 \text { and } n=1
\end{gathered}
$$

Proof:Let $G=T_{m, n}$ be a tadpole graph and define the vertex set $V(G)$ as in theorem 2.1. Consider

$$
\begin{aligned}
& H_{2}\left(T_{m, n}\right)=\sum_{v_{1} v_{2} \in E}\left[d_{G}\left(v_{1}\right) d_{G}\left(v_{2}\right)\right]^{2} \\
& =\sum_{E_{1}}\left[d_{2}\left(v_{1}\right) d_{2}\left(v_{2}\right)\right]^{2}+\sum_{E_{2}}\left[d_{3}\left(v_{1}\right) d_{2}\left(v_{2}\right)\right]^{2} \\
& +\sum_{E_{3}}\left[d_{3}\left(v_{1}\right) d_{1}\left(v_{2}\right)\right]^{2} \\
& =(m-2)(2 \times 2)^{2}+2(3 \times 2)^{2}+(3 \times 1)^{2} \\
& =16(m-2)+72+9 \\
& H_{2}\left(T_{m, n}\right)=16 m+49
\end{aligned}
$$

Now, for the second hyper-Zagreb polynomial of a $T_{m, n}$, we have

$$
\begin{aligned}
& H M_{2}\left(T_{m, n}, x\right)=\sum_{u v \in E} x^{\left[d_{G}\left(v_{1}\right) d_{G}\left(v_{2}\right)\right]^{2}} \\
& =\sum_{E_{1}} x^{\left[d_{2}\left(v_{1}\right) d_{2}\left(v_{2}\right)\right]^{2}}+\sum_{E_{2}} x^{\left[d_{3}\left(v_{1}\right) d_{2}\left(v_{2}\right)\right]^{2}} \\
& \quad+\sum_{E_{3}} x^{\left[d_{3}\left(v_{1}\right) d_{1}\left(v_{2}\right)\right]^{2}} \\
& =(m-2) x^{[2 \times 2]^{2}}+2 x^{[3 \times 2]^{2}}+x^{[3 \times 1]^{2}} \\
& =(m-2) x^{16}+3 x^{36}+x^{4} \\
& H M_{2}\left(T_{m, n}, x\right)=2 x^{36}+(m-2) x^{16}+x^{4}
\end{aligned}
$$

Theorem 2.4: The second HZbI and their polynomial of a Tadpole graph are

$$
\begin{aligned}
H M_{2}\left(T_{(m, n)}\right)= & 16 m+16 n+48 \text { where } m>3 \text { and } n \\
& >1 \\
H M_{2}\left(T_{m, n}, x\right)= & 3 x^{36}+(m+n-4) x^{16}+x^{4} \text { where } m \\
& >3 \text { and } n>1
\end{aligned}
$$

Proof: Let $G=T_{m, n}$ be a tadpole graph. As defined in theorem 2.1, we consider the vertex set $V(G)$.

Consider

$$
\begin{aligned}
& H M_{2}\left(T_{m, n}\right)=\sum_{v_{1} v_{2} \in E}\left[d_{G}\left(v_{1}\right) d_{G}\left(v_{2}\right)\right]^{2} \\
& =\sum_{E_{1}}\left[d_{2}\left(v_{1}\right) d_{2}\left(v_{2}\right)\right]^{2}+\sum_{E_{2}}\left[d_{3}\left(v_{3}\right) d_{2}\left(v_{2}\right)\right]^{2} \\
& +\sum_{E_{3}}\left[d_{2}\left(v_{1}\right) d_{1}\left(v_{2}\right)\right]^{2} \\
& =(m+n-4)(2 \times 2)^{2}+3(3 \times 2)^{2}+(2 \times 1)^{2} \\
& =16(m+n-4)+108+4 \\
& H_{2}\left(T_{m, n}\right)=16 m+16 n+48
\end{aligned}
$$

Now, for the second hyper-Zagreb polynomial of a $T_{m, n}$, we have

$$
H M_{2}\left(T_{m, n}, x\right)=\sum_{v_{1} v_{2} \in E} x^{\left[d_{G}\left(v_{1}\right) d_{G}\left(v_{2}\right)\right]^{2}}
$$

$$
\begin{aligned}
& =\sum_{E_{1}} x^{\left[d_{2}\left(v_{1}\right) d_{2}\left(v_{2}\right)\right]^{2}} \\
& \quad+\sum_{E_{2}} x^{\left[d_{3}\left(v_{1}\right) d_{2}\left(v_{2}\right)\right]^{2}}+\sum_{E_{3}} x^{\left[d_{2}\left(v_{1}\right) d_{1}\left(v_{2}\right)\right]^{2}} \\
& \quad=(m+n-4) x^{[2 \times 2]^{2}}+3 x^{[3 \times 2]^{2}}+x^{[2 \times 1]^{2}} \\
& \quad=(m+n-4) x^{16}+3 x^{36}+x^{4} \\
& H_{2}\left(T_{m, n}, x\right)=3 x^{36}+(m+n-4) x^{16}+x^{4}
\end{aligned}
$$

Corollary 2.5: The difference between first and second HZbI of a Tadpole graph $T_{m, n}$ where $(m>3$ and $n>1)$ is

$$
H M_{2}\left(T_{m, n}\right)-H M_{1}\left(T_{m, n}\right)=28
$$

Corollary 2.6: The difference between first and second HZbI of a Tadpole graph $T_{m, n}$, where $(m>3$ and $n=1)$ is

$$
H M_{2}\left(T_{m, n}\right)-H M_{1}\left(T_{m, n}\right)=15
$$

Corollary 2.7:The first HZbI of Tadpole graph is equal to sum of the first HZbI of cycle $C_{m}$ and path $P_{n}$. Where $(m>3$ and $n>1)$

$$
H M_{1}\left(T_{m, n}\right)=H M_{1}\left(C_{m}\right)+H M_{1}\left(P_{m}\right)
$$

Corollary 2.8: The first HZbI of Tadpole graph is equal to sum of first HZbI of cycle $C_{m}$ and sixteen times $n$. Where $(m>3$ and $n=1)$

$$
H M_{1}\left(T_{m, n}\right)=H M_{1}\left(C_{m}\right)+16 n
$$

Theorem 2.9: The Randic index of Tadpole graph $G$ are

$$
\aleph(G)=\frac{(m-2)}{2}+1.394 \text { where } m \geq 3 \text { and } n=1
$$

Proof: Consider the graph $G=T_{m, n}$ is a tadpole graph. We consider the vertex set $V(G)$ as defined in Theorem 2.1. We have,

$$
\begin{gathered}
\aleph(G)=\sum_{v_{1} v_{2} \in E(G)} \frac{1}{\sqrt{d_{G}\left(v_{1}\right) d_{G}\left(v_{2}\right)}} \\
=\sum_{v_{1} v_{2} \in E(G)} \frac{1}{\sqrt{d_{2}\left(v_{1}\right) d_{2}\left(v_{2}\right)}}+\sum_{v_{1} v_{2} \in E(G)} \frac{1}{\sqrt{d_{3}\left(v_{1}\right) d_{2}\left(v_{2}\right)}}+ \\
=(m-2) \frac{1}{\sqrt{2 \times 2}}+2 \frac{1}{\sqrt{3 \times 2}}+\frac{1}{\sqrt{3 \times 1}} \\
\aleph(G)=\frac{(m-2)}{2}+1.394
\end{gathered}
$$

Theorem 2.10: The Randic index Tadpole graphs are

$$
\aleph\left(T_{m, n}\right)==\frac{(m+n-4)}{2}+1.932 \text { where } m \geq 3 \text { and } n
$$

Proof: Let $G=T_{m, n}$ be a tadpole graph. Define $V(G)$ as in Theorem 2.1. Consider

$$
\begin{aligned}
& \aleph(G)=\sum_{v_{1} v_{2} \in E(G)} \frac{1}{\sqrt{d_{G}\left(v_{1}\right) d_{G}\left(v_{2}\right)}} \\
& =\sum_{v_{1} v_{2} \in E(G)} \frac{1}{\sqrt{d_{2}\left(v_{1}\right) d_{2}\left(v_{2}\right)}}+\sum_{v_{1} v_{2} \in E(G)} \frac{1}{\sqrt{d_{3}\left(v_{1}\right) d_{2}\left(v_{2}\right)}}+ \\
& \sum_{v_{1} v_{2} \in E(G)} \frac{1}{\sqrt{d_{2}\left(v_{1}\right) d_{1}\left(v_{2}\right)}} \\
& =(m+n-4) \frac{1}{\sqrt{2 \times 2}}+3 \frac{1}{\sqrt{3 \times 2}}+\frac{1}{\sqrt{2 \times 1}} \\
& \quad=\frac{(m+n-4)}{2}+1.932 \\
& \aleph(G)=\frac{(m+n-4)}{2}+1.932 \\
& \begin{array}{l}
\text { Published By: } \\
\text { Blue Eyes Intelligence Engineering }
\end{array}
\end{aligned}
$$


Theorem 2.11: The sum connectivity indexes of tadpole graph are

$$
X(G)=\frac{(m-2)}{2}+1.394 \text { where } m \geq 3 \text { and } n=1
$$

Proof: As defined in Theorem 2.1, we consider the set of vertices $V(G)$. We have

$$
\begin{gathered}
\aleph(G)=\sum_{v_{1} v_{2} \in E(G)} \frac{1}{\sqrt{d_{G}\left(v_{1}\right)+d_{G}\left(v_{2}\right)}} \\
=\sum_{v_{1} v_{2} \in E(G)} \frac{1}{\sqrt{d_{2}\left(v_{1}\right)+d_{2}\left(v_{2}\right)}}+\sum_{v_{1} v_{2} \in E(G)} \frac{1}{\sqrt{d_{3}\left(v_{1}\right)+d_{2}\left(v_{2}\right)}} \\
+\sum_{v_{1} v_{2} \in E(G)} \frac{1}{\sqrt{d_{3}\left(v_{1}\right)+d_{1}\left(v_{2}\right)}} \\
\kappa(G)=\frac{1}{2}+2 \frac{1}{\sqrt{2+2}}+\frac{1}{\sqrt{3+1}} \\
N(m)
\end{gathered}
$$

Theorem 2.12: The sum connectivity indexes of tadpole graph are

$$
X(G)=\frac{(m+n-4)}{2}+1.919 \text { where } m \geq 3 \text { and } n>1
$$

Proof: We denote sum connectivity $X(G)$ and let $G=T_{m, n}$ be

$$
\begin{aligned}
& X(G)=\sum_{v_{1} v_{2} \in E(G)} \frac{1}{\sqrt{d_{G}\left(v_{1}\right)+d_{G}\left(v_{2}\right)}} \\
& =\sum_{v_{1} v_{2} \in E(G)} \frac{1}{\sqrt{d_{2}\left(v_{1}\right)+d_{2}\left(v_{2}\right)}}+\sum_{v_{1} v_{2} \in E(G)} \frac{1}{\sqrt{d_{3}\left(v_{1}\right)+d_{2}\left(v_{2}\right)}}+ \\
& \sum_{v_{1} v_{2} \in E(G)} \frac{1}{\sqrt{d_{2}\left(v_{1}\right)+d_{1}\left(v_{2}\right)}} \\
& =(m+n-4) \frac{1}{\sqrt{2+2}}+3 \frac{1}{\sqrt{3+2}}+\frac{1}{\sqrt{2+1}} \\
& =\frac{(m+n-4)}{2}+1.919
\end{aligned}
$$

Consider

Theorem 2.13: The atom-bond connectivity index of tadpole graph is

$$
A B C(G)=\frac{m+n}{\sqrt{2}}+2.231 \text { where } m \geq 3 \text { and } n=1
$$

Proof: Let $G=T_{m, n}$ be a tadpole graph. Consider

$$
=
$$

$\sum_{v_{1} v_{2} \in E(G)} \sqrt{\frac{d_{2}\left(v_{1}\right)+d_{2}\left(\left(v_{2}\right)-2\right.}{d_{2}\left(v_{1}\right) d_{2}\left(\left(v_{2}\right)\right.}}+$

$\sum_{v_{1} v_{2} \in E(G)} \sqrt{\frac{d_{3}\left(v_{1}\right)+d_{2}\left(\left(v_{2}\right)-2\right.}{d_{3}\left(v_{1}\right) d_{2}\left(\left(v_{2}\right)\right.}}+\sum_{v_{1} v_{2} \in E(G)} \sqrt{\frac{d_{2}\left(v_{1}\right)+d_{1}\left(\left(v_{2}\right)-2\right.}{d_{G}\left(v_{1}\right) d_{G}\left(\left(v_{2}\right)\right.}}$

$=(m-2) \sqrt{\frac{2+2-2}{2 \times 2}}+2 \sqrt{\frac{3+2-2}{3 \times 2}}+\sqrt{\frac{3+1-2}{3 \times 1}}$

$A B C(G)=\frac{m-2}{\sqrt{2}}+2.231$

Theorem 2.14: The atom-bond connectivity index of tadpole graph is

$$
A B C(G)=\frac{m+n}{\sqrt{2}} \text { where } m \geq 3 \text { and } n>1
$$

Proof: Let $G=T_{m, n}$ be a tadpole graph. Consider

$$
A B C(G)=\sum_{v_{1} v_{2} \in E(G)} \sqrt{\frac{d_{G}\left(v_{1}\right)+d_{G}\left(\left(v_{2}\right)-2\right.}{d_{G}\left(v_{1}\right) d_{G}\left(\left(v_{2}\right)\right.}}
$$

$$
A B C(G)=\sum_{v_{1} v_{2} \in E(G)} \sqrt{\frac{d_{G}\left(v_{1}\right)+d_{G}\left(\left(v_{2}\right)-2\right.}{d_{G}\left(v_{1}\right) d_{G}\left(\left(v_{2}\right)\right.}}
$$

$$
\begin{aligned}
& = \\
& \sum_{v_{1} v_{2} \in E(G)} \sqrt{\frac{d_{2}\left(v_{1}\right)+d_{2}\left(\left(v_{2}\right)-2\right.}{d_{2}\left(v_{1}\right) d_{2}\left(\left(v_{2}\right)\right.}}+ \\
& \sum_{v_{1} v_{2} \in E(G)} \sqrt{\frac{d_{3}\left(v_{1}\right)+d_{2}\left(\left(v_{2}\right)-2\right.}{d_{3}\left(v_{1}\right) d_{2}\left(\left(v_{2}\right)\right.}}+\sum_{v_{1} v_{2} \in E(G)} \sqrt{\frac{d_{2}\left(v_{1}\right)+d_{1}\left(v_{2}\right)-2}{d_{2}\left(v_{1}\right) d_{1}\left(\left(v_{2}\right)\right.}} \\
& =(m+n-4) \sqrt{\frac{2+2-2}{2 \times 2}}+3 \sqrt{\frac{3+2-2}{3 \times 2}}+\sqrt{\frac{2+1-2}{2 \times 1}} \\
& \quad A B C(G)=\frac{m+n}{\sqrt{2}}
\end{aligned}
$$

III. RESULTS

3.1 First hyper index and polynomial

\begin{tabular}{|l|l|l|l|}
\hline $\begin{array}{c}\text { Sl. } \\
\text { No }\end{array}$ & \multicolumn{1}{c|}{$\begin{array}{c}\text { Notation and } \\
\text { Graph }\end{array}$} & $\begin{array}{c}\text { First hyper } \\
\text { index }\end{array}$ & \multicolumn{1}{|c|}{ Polynomial } \\
\hline $\mathbf{1}$ & $\begin{array}{l}H M_{1}\left(T_{(m, n)}\right) \\
\text { where } m \\
\geq 3 \text { and } n>1\end{array}$ & $\begin{array}{l}16 m+16 n \\
+20\end{array}$ & $\begin{array}{l}3 x^{25} \\
+(m+n-4) x^{16} \\
+x^{9}\end{array}$ \\
\hline $\mathbf{2}$ & $\begin{array}{l}H M_{1}\left(T_{(m, n)}\right) \\
m \geq 3 \text { and } n \\
=1\end{array}$ & $16 m+34$ & $2 x^{25}+(m-1) x^{16}$ \\
\hline
\end{tabular}

\subsection{Second hyper index and polynomial}

\begin{tabular}{|c|l|l|l|}
\hline $\begin{array}{c}\text { Sl. } \\
\text { No }\end{array}$ & $\begin{array}{c}\text { Notation and } \\
\text { Graph }\end{array}$ & $\begin{array}{c}\text { Second } \\
\text { hyper } \\
\text { index }\end{array}$ & Polynomial \\
\hline $\mathbf{1}$ & $\begin{array}{c}H M_{2}\left(T_{(m, n)}\right) \\
\text { where } m \\
\geq 3 \text { and } n>1\end{array}$ & $\begin{array}{l}16 m+16 n \\
+48\end{array}$ & $\begin{array}{l}3 x^{36} \\
+(m+n-4) x^{16} \\
+x^{4}\end{array}$ \\
\hline $\mathbf{2}$ & $\begin{array}{ll}H M_{2}\left(T_{(m, n)}\right) \\
m \geq 3 \text { and } n \\
=1\end{array}$ & $16 m+49$ & $\begin{array}{l}3 x^{36} \\
+(m+n-4) x^{16} \\
+x^{4}\end{array}$ \\
\hline
\end{tabular}

3.3 The difference between first and second hyper-Zagreb index

\begin{tabular}{|c|c|c|}
\hline $\begin{array}{c}\text { Sl. } \\
\text { No }\end{array}$ & Graph & Difference \\
\hline $\mathbf{1}$ & $H M_{1}\left(T_{(m, n)}\right)$ & $\mathbf{2 8}$ \\
\hline $\mathbf{2}$ & $\begin{array}{l}H M_{1}\left(T_{(m, n)}\right) \\
m \geq 3 \text { and } n=1\end{array}$ & $\mathbf{1 5}$ \\
\hline
\end{tabular}

\subsection{Connectivity indices}

Published By:

Blue Eyes Intelligence Engineering 


\begin{tabular}{|c|c|c|c|}
\hline Sl.no & $\begin{array}{c}\text { Notation } \\
\text { and Graph }\end{array}$ & $\begin{array}{l}\boldsymbol{m} \geq \mathbf{3} \text { and } \boldsymbol{m} \\
>1\end{array}$ & $\begin{array}{l}\boldsymbol{m} \geq \mathbf{3} \text { and } \boldsymbol{1} \\
=\mathbf{1}\end{array}$ \\
\hline 1 & $\aleph\left(T_{(m, n)}\right)$ & $\frac{(m+n-4)}{2}$ & $\frac{(m-2)}{2}$ \\
+1.932 & $\frac{(m+n-4)}{2}$ & $\frac{(m-2)}{2}$ \\
\hline 2 & $X\left(T_{(m, n)}\right)$ & $\frac{(m .394}{+1.919}$ & $\frac{m-2}{\sqrt{2}}+2.231$ \\
\hline 3 & $A B C\left(T_{(m, n)}\right)$ & $\frac{m+n}{\sqrt{2}}$ & \\
\hline
\end{tabular}

\section{CONCLUSION}

$>$ For the Tadpole graph first HZblis equal to sum of the first HZbIof cycle and path. $\operatorname{Here}\left(G=T_{m, n}\right.$ where $m>3$ and $\left.n>1\right)$.

$>$ For the Tadpole graph first HZbI isequal to sum of the first HZbI of cycle and sixteen times $n$. Here $(G=$ $T m, n$ where $m>3$ and $n=1$ ).

$>$ The Randic index of Tadpole graph is equal to the sum connectivity indexes of tadpole graph. where $m \geq$ 3 and $n=1$.

\section{ACKNOWLEDGMENTS}

We the authors are very much thankful to the management and staff of Department of Mathematics, Sri Venkateshwara College of Engineering, Bangalore and HKBK Engineering College, Bangalore, for their support and encouragement. The authors also acknowledge the valuable suggestions from anonymous referees which led to the enhancement of the manuscript.

\section{REFERENCES}

1. B. Chaluvaraju, H.S. Boregowda and S.A. Diwakar, Zagreb indices and their polynomials of certain classes of windmill graphs, submitted.

2. B. Zhou and N. Trinajstic, On a novel connectivity index, J. Math. Chem.46(2009)1252-1270.

3. E. Estrada, L. Torres, L. Rodriguez and I. Gutman, An atom-bond connectivity index: Modelling the enthalphy of formation of alkanes, Indian J. Chem. 37A (1998)849-855.

4. G.H Fath-Tabar, Zagreb polynomial and Pi Indices of some Nano Structures, Digest Journal of Nanomaterials and Biostructures, 4(1)(2009), 189-191.

5. G.H. Fath-Tabar, old and new Zagreb indices of graphs, MATCH communications in Mathematical and Computer chemistry, 65(2011), 79-84.

6. G.H. Shirdel, H. Rezapour and A.M.Sayadi, The hyper-Zagreb index of graph operations, Iran J.Math Chem.4(2)(2013), 213-220.

7. M. Randic, On characterization of molecular branching, J. Am. Chem. Soc.,97(1975) 6609-6615.

8. M.R.Farahani, Computing the hyper-Zagreb index of hexagonal nanotubes, J. Chem.Mat.Res. 2(1)(2015)16-18.

9. M.R. Farahani, M.R. Rajesh Kanna and R. Pradeep Kumar, on the hyper-Zagerb indices of some nanostructurs, Asain Academic Research J. Multidisciplinary, 3(1)(2007),1-58.

10. M.R. Farahani, M.R. Rajesh Kanna and R. Pradeep Kumar, on the hyper-Zagerb indices of some nanostructurs, Asain Academic Research J. Multidisciplinary, 3(1)(2016),115-123.

11. J.A.Gallian, Dynamic Survey DS6: Graph Labeling, Electronic J.Combin,DS6(2007),1-58, Jan 3,2007.

12. W. Gao, M.K Jamil, M. R. Farahani, The hyper-Zagreb index and some graph operations, J. Appl. Math. Comput.(2016)1-13.

13. I Gutman, Degree-based topological indices, Croat. Chem. Acta.86(2013), 351-361.

14. I.Gutman K.C. Das, The first Zagreb indices 30 years after, MATCH Commun.Math.Compu. Chem. 50(2004), 83-92.

15. I.Gutman, V.R. Kulli, B. Chaluvaraju and H.S. Boregowda, On Banhatti and Zagreb Indices. J.Int. Math. Virtual Insst.7(2017), 53-67.

16. I.Gutman and N.Trinajstic, Graph Theory and molecular obtains, Total $\pi$-electron energy of alternant hydrocarbons, Chem.Phys.Lett.17(1972),535-538.

17. V.R.Kulli, College Graph Theory, Vishwa International Publications, Gulbarga, India(2012).

18. V.R.Kulli, B. Chaluvaraju and H. S. Boregowda, Some degree based connectivity indices of Kulli cycle windmill graph, South Assain J.Maths6(6), 263-268

19. V.R.Kulli, B. Chaluvaraju and H.S. Boregowda, computation of connectivity indices of Kulli path windmill graph, TWMS J. Appl. Eng.Math., to appear(2017).

20. R.Todeschini, V.Consonni Molecular Dercriptors for Chemoinformatics, Wiley-VCH, Weinheim(2009).

\section{AUTHORS PROFILE}

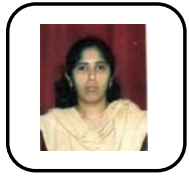

journals.

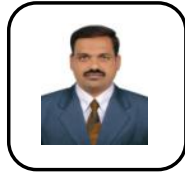
research papers in reputed international journals.

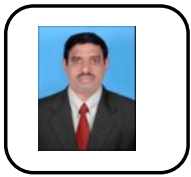

Nagabhushana C S,presently working as a professor in the Department of Mathematics, H.K.B.K EngineeringCollege, Bangalore. He Completed his Ph.D. degree in 2012 from Bangalore University, Bangalore. His research work on Numerical quadrature and Graph theory. He published 10 research paper in reputed international journals. 